\title{
Probing the Relationship between Vocabulary Knowledge and Listening Comprehension of Iranian Lower-Intermediate EFL Learners
}

\author{
Mohammad Taghi Farvardin (Corresponding author) \\ Department of English Language Teaching, Ahvaz Branch, Islamic Azad University, Ahvaz, Iran \\ Email: farvardin@iauahvaz.ac.ir \\ Leila Valipouri \\ University of Applied Sciences and Technology, Boroujerd Branch, Boroujerd, Iran
}

Received: 28-03-2017

Published: 01-09-2017
Accepted: 10-05-2017

doi:10.7575/aiac.ijalel.v.6n.5p.273
Advance Access Published: July 2017

URL: http://dx.doi.org/10.7575/aiac.ijalel.v.6n.5p.273

\begin{abstract}
This study probed the relationship between vocabulary knowledge (i.e., size and depth) and listening comprehension of Iranian lower-intermediate EFL learners. To this end, 80 lower-intermediate EFL learners in Ahvaz, Iran, were selected. This study also investigated the predictive power of the vocabulary size and depth in lower-intermediate EFL learners' listening comprehension. To this end, three tests (i.e., Vocabulary Levels Test, Word Associates Test, and a listening comprehension test) were administered to the participants. The results of Pearson correlations and multiple regression analyses revealed that vocabulary depth had a higher relationship with the listening comprehension scores $(r=0.43, p<$ .01). In addition, vocabulary depth proved to be a more powerful predictor of listening comprehension scores.
\end{abstract}

Keywords: vocabulary knowledge, vocabulary size, vocabulary depth, listening comprehension, lower-intermediate EFL learners

\section{Introduction}

Recently, accumulating attention has been paid to research on vocabulary knowledge in second language (L2) learning because of the key role lexical knowledge plays in learners' communicative competence (Meara, 2002). The main element, in effect, which connects the four skills of speaking, listening, reading and writing together is vocabulary (Hedge, 2002). In the area of language learning, vocabulary knowledge has been equated with success in L2 or foreign language learning (Laufer \& Goldstein, 2004).

Language learners, generally, believe that many of their difficulties in both receptive and productive skills arise from their inadequate vocabulary knowledge (Nation, 1990). Moreover, "the challenge of acquiring a large enough vocabulary for successful communication in a variety of settings has been the focus of much recent research" (Lightbown \& Spada, 2006, p. 96).

Some researchers (e.g., Meara, 1996; Qian, 1999; Schmitt, 2014) divided vocabulary knowledge into two important aspects, i.e. breadth or size of vocabulary and depth. Qian (2002) proposed that vocabulary size refers to the number of words of which a learner has at least some superficial knowledge of meaning, while vocabulary depth includes all lexical characteristics such as phonemic, grapheme, syntactic, semantic, collocation, and phraseological properties, as well as frequency and register. Vocabulary depth is also defined by Schmitt (2000) as syntactic properties, possible collocations, pragmatic rules and semantic representation of the words or concepts.

Most studies on language proficiency and vocabulary knowledge have concentrated on vocabulary size because measuring vocabulary size is more accessible and easier than vocabulary depth (e.g., Laufer \& Goldstein, 2004; Stæhr, 2008). However, some researchers (e.g., Schmitt \& Meara, 1997; Wesche \& Paribakht, 1996) asserted that a vocabulary test should measure the depth of word knowledge as well. The most widely used vocabulary size test for L2 studies is the Vocabulary Levels Test (VLT), which is at first developed by Nation (1990) and then modified by Schmitt, Schmitt and Clapham (2001). According to Meara (1996), VLT is "the nearest thing we have to a standard test in vocabulary" (p. 38). In a number of studies (e.g., Farvardin \& Koosha, 2011; Stæhr, 2009; Wen, 2014), this test has been used as a reliable and valid vocabulary size measure. Breadth or size tests provide basic measures of a learner's overall vocabulary knowledge, but they were criticized for indicating shallow and superficial rather than deeper knowledge of individual words (Read, 2000).

Listening comprehension is a key factor in communication and of the total time spent on communicating, listening takes up 40-50\%; speaking, 25-30\%; reading, 11-16\%; and writing, about 9\% (Mendelsohn, 1994). One of the major obstacles to successful listening comprehension of the L2 learners is lack of vocabulary knowledge (Kelly, 1991). To 
delve more into this issue, more research should be conducted on the role of different aspects of vocabulary knowledge, i.e. size and depth, and listening comprehension.

Listening, for a long time, has been regarded as the Cinderella skill (Flowerdew \& Miller, 2005). The main listening problems in L2 arise from vocabulary knowledge and attention failure (Goh, 2000). Thus, there is a great need to conduct research on different aspects of vocabulary knowledge, depth and size, and listening comprehension. To the best of the researchers' knowledge, little research (Feng, 2014; Stæhr, 2009; Wen, 2014) has been carried out on the relationship between vocabulary knowledge and listening comprehension. Thus, the present study is motivated by a critical lack of empirical research on the relationship between vocabulary knowledge and listening comprehension, especially in Iran as an EFL context.

Few studies have probed the role of vocabulary knowledge in listening comprehension (e.g., Feng, 2014; Stæhr, 2009; Wen, 2014). Stæhr (2009) conducted an empirical study investigating the role of vocabulary knowledge in listening comprehension. One hundred fifteen advanced Danish EFL learners were recruited. The results showed that both dimensions of vocabulary knowledge, depth and breadth, were significantly correlated with listening comprehension and could predict half of the variance in the listening scores. Stepwise multiple regression analysis was conducted showed that vocabulary size alone accounted for a significant $49 \%$ of the variance in listening comprehension implying that vocabulary size is the basic component of vocabulary knowledge in listening comprehension. Stæhr (2009) asserted that a vocabulary size of at least 5000 word families might provide a significant prediction in successful listening comprehension.

In the same line, Wen (2014) carried out a study on 156 university EFL learners. The results revealed that both size and depth had a significant correlation with listening comprehension, but vocabulary size produced a slightly higher correlation ( $r=0.495$ compared to 0.479 ). According to the multiple regression analysis, vocabulary size made the greatest contribution to listening comprehension predicting $24.5 \%$ of the variance in listening comprehension scores.

In another study, Feng (2014) examined the role of depth and breadth of vocabulary knowledge in listening comprehension of 88 Chinese learners who had already passed the College English Test 4 (CET). The results showed that the depth of vocabulary knowledge provided a higher correlation $(r=0.91)$ with listening comprehension and a higher predictive power in listening comprehension than the size of vocabulary knowledge.

Despite the renewed interest in vocabulary knowledge studies, most empirical studies have been concentrated on vocabulary size. Therefore, more empirical evidence on the role of vocabulary knowledge, especially vocabulary depth, in EFL students' listening comprehension performance is required. In other words, it is essential to probe the relationship between vocabulary knowledge and listening comprehension, and thereby explore to what extent that vocabulary knowledge can contribute to EFL listening comprehension at lower levels of language proficiency. To fill in the existing gap, the present study aimed to answer the following research questions:

Q1: To what extent do vocabulary size and listening comprehension of Iranian lower-intermediate EFL learners correlate?

Q2: To what extent do vocabulary depth and listening comprehension of Iranian lower-intermediate EFL learners correlate?

Q3: Which aspect of vocabulary knowledge (i.e., size or depth) is a stronger predictor of listening comprehension scores of Iranian lower-intermediate EFL learners?

\section{Method}

\subsection{Participants}

Eighty (56 female and 24 male) lower-intermediate EFL learners studying at two English institutes in Ahvaz, Iran, participated in this study. The participants were selected from six intact classes. The participants' age ranged from 18 to $27(M=23.30, S D=1.75)$. The participants' English proficiency was determined through Oxford Placement Test (OPT) (Allen, 2004) that including 200 items. Each correct item received 1 point. Therefore, the maximum possible score was 200. It was found that the participants were at lower-intermediate level of English proficiency. The band score for lower-intermediate level is 120 to 134 .

\subsection{Instruments}

\subsubsection{Listening Comprehension Test (LCT)}

The material for testing listening comprehension was selected from the Longman TOEFL PBT (Phillips, 2001). KR-20 reliability coefficient of LCT was 0.79 . The participants listened to 30 short conversations on a CD player and then responded to the multiple-choice questions in 20 minutes. The rationale for selecting this particular test was the familiarity of the test format to all participants, i.e. multiple-choice format.

\subsubsection{Vocabulary Levels Test (VLT)}

In order to assess the participants' vocabulary size, Schmitt et al.'s (2001) Vocabulary Levels Test (VLT), version 1, with a word-meaning matching format was used. In this study, the reliability of the VLT computed by KuderRichardson 20 (KR-20) formula was 0.81. This test has been accepted by prominent L2 lexical scholars (Qian, 2002). The VLT consists of five different sections (2000 words, 3000 words, 5000 words, university vocabulary level, and 10000 words); each section represents a different vocabulary level in English ranging from high-frequency to lowfrequency words. Each level of the test includes 30 items. The maximum possible score is 150 with one point for each 
item at the five levels. Selecting this test had three reasons: First, it is accepted and administered by a number of researchers (e.g., Laufer \& Kalovski, 2010; Stæhr, 2008, 2009). Second, VLT can be administered easily and within a short period of time. Third, unlike other standard multiple choice tests, the VLT reduces the chances of guessing to one response in six distractors.

\subsubsection{Word Associates Test (WAT)}

The most utilized measure of vocabulary depth is Read's (1998) Word Associates Test (WAT). It is one of the dimensions tests which assess word associations or associates linked to each target word. The test used in the present study was version 4.0 of the WAT. WAT consists of 40 items. In each item there is a stimulus word at the top with four synonyms in the right box and four associates or collocation in the left box. In scoring, each word correctly chosen was awarded one point. The maximum possible score, therefore, is 160 for the 40 items. The required time for this test is 30 minutes. The split-half reliability of the test is 0.89 (Qian, 2002). The reliability coefficient of the WAT computed in this study was 0.86 .

\subsection{Procedures}

The data was collected from 80 lower-intermediate EFL learners studying at two English institutes in Ahvaz, Iran. The tests were administered in two sessions. It took the participants 85 minutes to complete the VLT, WAT and TOEFL LCT, respectively. At the first session, VLT was administered in 35 minutes and WAT was administered in 30 minutes. At the second session, TOEFL LCT was administered in 20 minutes. Test instructions had been fully explained to the participants. All participants were informed that the data would be kept confidential, and that the purpose for writing their names was only to match the relevant test sheets. Table 1 shows the data collection procedure.

Table 1. Data Collection Procedure

\begin{tabular}{lll}
\hline Test & Time & Session \\
\hline VLT & 35 & First \\
WAT & 30 & First \\
LCT & 20 & Second \\
\hline
\end{tabular}

\subsection{Data Analysis}

To answer the first and second research questions, the scores of VLT, WAT, and the TOEFL LCT were entered SPSS, version 20, to examine the relationship between vocabulary size, depth of vocabulary knowledge, and listening comprehension. Then, two-tailed Pearson correlations were computed. To answer the third research question and determine the stronger predictor of listening comprehension, the multiple regression analysis was applied. Based on the previous studies discussed in the review of the literature, vocabulary depth and size were regarded as the independent variables and listening comprehension was considered as the dependent variable.

\section{Results}

The mean, standard deviation and reliability of the three test scores (i.e., LCT, VLT and WAT) are displayed in Table 2.

Table 2. Descriptive Statistics

\begin{tabular}{ccccc}
\hline Test & N & Mean & SD & Reliability \\
\hline VLT & 80 & 68.42 & 8.63 & 0.81 \\
WAT & 80 & 75.57 & 10.25 & 0.86 \\
LCT & 80 & 10.38 & 3.14 & 0.79 \\
\hline
\end{tabular}

As Table 2 shows, the mean and standard deviation of VLT were 68.42 and 8.63. The mean and standard deviation of WAT were 75.57 and 10.25. The mean score for LCT was $10.38(S D=3.14)$. Two-tailed Pearson correlations were computed between the scores of VLT, WAT, and LCT to determine the relationship between the two dimensions of vocabulary knowledge, size and depth, and listening comprehension.

Table 3. Pearson Correlation Coefficients

\begin{tabular}{lccc}
\hline & 1 & 2 & 3 \\
\hline 1. Vocabulary Size & - & & \\
2. Vocabulary Depth & 0.67 & - & \\
3. Listening Comprehension & 0.32 & 0.43 & - \\
\hline
\end{tabular}


As depicted in Table 3, the results of two-tailed Pearson correlation analysis show significantly moderate relationship between the participants' scores on the LCT, VLT and WAT. It was detected that statistically significant correlations were found among the scores of the three tests. Both vocabulary size and vocabulary depth have statistically significant correlation with listening comprehension. Vocabulary size is significantly correlated with listening comprehension $(p<$ $.01)$. Vocabulary size produced a correlation of 0.32 indicating a moderate relationship. Depth of vocabulary knowledge demonstrated a slightly higher correlation of 0.43 with listening comprehension. The correlation between VLT and WAT showed the highest 0.67 . To answer the third question, multiple regression analysis was conducted. Table 4 is the model summary and shows R, R square, Adjusted R square, and Standard Error of the Estimate.

Table 4. Model Summary

\begin{tabular}{lllll}
\hline Model & $\mathrm{R}$ & $\mathrm{R}^{2}$ & Adjusted R $^{2}$ & Std. Error of the Estimate \\
\hline 1 & 0.41 & 0.25 & 0.21 & 3.578 \\
\hline
\end{tabular}

The multiple regression analysis shows that vocabulary size and depth of vocabulary knowledge together account for $41 \%$ of the variance in the listening scores. Table 4 illustrates that the two variables, vocabulary size and depth of vocabulary knowledge, together could predict less than half of the variance in the listening scores. This result represents a significant contribution and indicates a moderate relationship between learner's vocabulary knowledge and the quality of his/her listening comprehension. To determine the more powerful predictor of listening comprehension, scores on VLT and WAT were taken as the predictor (or independent) variables and scores on the LCT as the dependent variable. In order to compare the unique contribution of each independent variable (depth and size), the Beta values were computed (see Table 5).

Table 5. Multiple Regressions

\begin{tabular}{lll}
\hline & Beta & Sig \\
\hline (Constant) & & 0.26 \\
\hline Vocabulary Size & 0.13 & 0.34 \\
\hline Vocabulary Depth & 0.28 & 0.00 \\
\hline
\end{tabular}

As Table 5 shows, the Beta value of the predictor variable, vocabulary depth, was (Beta $=0.28, p<.01)$ in comparison to the Beta value of the predictor variable, vocabulary size, (Beta $=0.13, p>.01)$. This means that vocabulary depth as the independent variable made a stronger contribution to the dependent variable, listening comprehension. Vocabulary depth alone accounted for $0.28 \%$ of the variance in the dependent variable, listening comprehension. Thus, vocabulary depth, as a predictor, explained a significant amount of the LCT variance. In other words, vocabulary size did not explain a significant proportion of listening comprehension variance $($ Beta $=0.172, p>.05)$. This suggests that vocabulary depth is the basic component of vocabulary knowledge in listening comprehension and thus vocabulary size could not have a strong role in listening comprehension tests.

\section{Discussion and Conclusion}

The results showed that the correlation between vocabulary size and listening comprehension was high and significant $(r=0.32, p<.01)$. This finding is in line with some studies in both ESL and EFL contexts (e.g., Feng, 2014; Stæhr, 2008, 2009; Wen, 2014) which reported moderate correlation between vocabulary size and listening comprehension. These results assert that receptive vocabulary knowledge is almost as important for listening as it is for reading, although stronger relationship has been found between vocabulary size and reading comprehension (e.g., Stæhr, 2008). Vocabulary size produced a correlation of 0.32 which indicates a moderate relationship between the size of a learner's receptive vocabulary and the quality of that learner's listening comprehension. This relationship between vocabulary size and listening comprehension is similar to that related to reading- knowing a large number of words will provide the learner with a large lexical coverage of any given test and so the learner will achieve adequate listening comprehension. Thus, vocabulary size could still be regarded as a significant feature in learners' listening comprehension.

Besides the findings on vocabulary size and lexical coverage, the data of the current study demonstrated that depth of vocabulary knowledge, operationalized through the Word Associates Test (WAT), correlates significantly with listening comprehension $(r=0.43, p<.01)$ and could contribute significantly to the prediction of the listening scores. Though, it was found that the two dimensions of vocabulary knowledge were highly correlated with listening comprehension, depth of vocabulary knowledge in this study demonstrated higher correlation $(r=0.43)$ than vocabulary breadth $(r=$ 0.32 ) with listening comprehension.

Findings of this study are consistent with the findings of Feng (2014), Mehrpour et al. (2011), and Qian (1999, 2002). However, these findings are not congruent with Stæhr's (2009) and Wen's (2014) findings of the correlation level between the depth and breadth of vocabulary knowledge and listening comprehension. In both studies vocabulary size 
showed a higher correlation with listening comprehension. It might be explained that in Stæhr (2009) and Wen (2014) studies, the breadth and depth of vocabulary knowledge may have employed into the same dimension of vocabulary knowledge because only the receptive meaning of targeted knowledge was measured, while the productive level of vocabulary was not addressed. Another reason of this difference might be that WAT (depth measure) probes more into the various aspects of the collocations, synonymous and part-whole, whole-part relationships of the given words while the VLT measures only the meaning of the target words. The third reason would be that although depth is a consequence of knowing many words, it does not mean that the more words a learner knows, the more links between words they will form, and the more elaborate structure of the network will be established. Therefore, more attention should be given to the depth of vocabulary knowledge in teaching listening comprehension, since it has been found that vocabulary depth has a substantial prediction in listening scores. In order to achieve this purpose, more understanding of the depth of vocabulary knowledge is recommended and the learners should provide with a more advanced semantic processing ability with either familiar or unfamiliar words in many activities, such as word-level competency.

The multiple regression analysis in this study showed that vocabulary size and depth of vocabulary knowledge together account for $41 \%$ (more than half) of the variance in the listening scores. This significant contribution indicates that these dimensions are important factors for successful listening comprehension in English. Thus, findings of this study reveal a lot of similarities to other research studies in different contexts (e.g., Farvardin \& Koosha, 2011; Feng, 2014; Stæhr, 2009). Hence, the dimensions of vocabulary knowledge, breadth and depth, are closely related to listening comprehension. Results are consistent with Feng (2014), Mehrpour et al. (2013) and Qian (2002). Mehrpour et al. (2013) revealed that a Beta index of the depth of vocabulary knowledge was 0.46 while the Beta index of vocabulary size was 0.32 . Thus, vocabulary depth was a stronger predictor of reading comprehension and had a stronger effect on reading comprehension scores. It means that if the relationship between vocabulary depth and listening had been strong enough, vocabulary depth, in addition to vocabulary size, would also have contributed substantially to the variance in the listening scores. Feng (2014) computed that the depth of vocabulary knowledge with $\mathrm{R}=0.94$ added $2.6 \%$ variance to the vocabulary size, so vocabulary depth had a significant predictive power on the scores of listening comprehension.

However, the findings of this study are not consistent with those of Stæhr (2009) and Wen (2014). In Stæhr's (2009) study vocabulary size accounted for a significant $49 \%$ of the variance in listening comprehension. Therefore, he concluded that vocabulary size is the basic component of vocabulary knowledge in listening comprehension and that depth of vocabulary knowledge does not play a separate role. Wen (2014) showed that vocabulary breadth can predict $24.5 \%$ of the variance in listening comprehension scores, while vocabulary depth covariance was $23 \%$. This discrepancy in findings between the current study and those of Stæhr (2009) and Wen (2014) might be due to the fact that participants of this study are exposed to a less-varied language input in comparison to these studies.

Future research would benefit from the current study in many ways. First, only two components of vocabulary depth, association and collocation, were examined. In other words, other components such as morphology, register and frequency need to be investigated to better understand what impact these components of vocabulary depth might have on listening comprehension under different conditions. Second, findings of this study demonstrated a positive and significant relationship between vocabulary knowledge and listening, but it was not investigated whether vocabulary knowledge was the direct causal factor in listening comprehension. Thus, examining causality in the relationship between vocabulary and listening may be useful. Finally, since vocabulary acquisition is incremental by nature (Schmitt, 2014), longitudinal studies on how learners acquire vocabulary knowledge can be conducted.

\section{References}

Allan, D. (2004). Oxford Placement Test 2: Test Pack. Oxford: Oxford University Press.

Farvardin, M. T., \& Koosha, M. (2011). The role of vocabulary knowledge in Iranian EFL students' reading comprehension performance: Breadth or depth? Theory and Practice in Language Studies, 1, 1575-1580.

Feng, T. (2014). Assessing the depth and breadth of vocabulary knowledge with listening comprehension. PASAA, 48, 29-56.

Flowerdew, J., \& Miller, L. (2005). Second language listening: theory and practice. New York: Cambridge University Press.

Goh, C. M. (2000). A cognitive perspective on language learners' listening comprehension problems. System, 28(1), 5575.

Hedge, T. (2002). Teaching \& learning in the language classroom. Shanghai: Shanghai Foreign Language Education Press.

IBM SPSS Statistics for Windows (Version 20). Armonk, NY: IBM Corp.

Kelly, P. (1991). Lexical ignorance: The main obstacle to listening comprehension with advanced foreign language learners. International Review of Applied Linguistics, 29, 135-149.

Laufer, B., \& Goldstein, Z. (2004). Testing vocabulary knowledge: Size, strength, and computer adaptiveness. Language Learning, 54, 399-436.

Laufer, B., \& Kalovski, G. (2010). Lexical threshold revisited: Lexical text coverage, learners' vocabulary size and reading comprehension. Reading in a Foreign Language, 22(1), 15-30. 
Lightbown, P. M., \& Spada, N. (2006). How languages are learned (3rd ed.). Oxford: Oxford University Press.

Meara, P. (1996). The dimensions of lexical competence. In G. Brown, K. Malmkjaer, \& J. Williams (Eds.), Performance and competence in second language acquisition (pp. 35-53). New York: Cambridge University Press.

Meara, P. (2002). The rediscovery of vocabulary. Second Language Research, 18(4), 393-407.

Mehrpour, S., Razmjoo, S. A., \& Kian, P. (2011). The relationship between depth and breadth of vocabulary knowledge and reading comprehension among Iranian EFL learners. Journal of English Language Teaching and Learning, 53(222), 97-127.

Mendelsohn, D. J. (1994). Learning to listen: A strategy-based approach for the second language learner. San Diego: Dominie Press.

Nation, I. S. P. (1990). Teaching and learning vocabulary. Rowley, MA: Newbury House.

Phillips, D. (2001). Longman complete course for the TOEFL test: Preparation for the computer and paper tests. USA: Longman.

Qian, D. D. (1999). Assessing the roles of depth and breadth of vocabulary knowledge in reading comprehension. Canadian Modern Language Review, 56, 282-307.

Qian, D. D. (2002). Investigating the relationship between vocabulary knowledge and academic reading performance: An assessment perspective. Language Learning, 52, 513-536.

Read, J. (1998). Validating a test to measure depth of vocabulary knowledge. In A. Kunnan (Ed.), Validation in language assessment (pp. 41-60). Mahwah, NJ: Erlbaum.

Read, J. (2000). Assessing vocabulary. New York: Cambridge University Press.

Schmitt, N. (2000). Vocabulary in language teaching. Cambridge University Press, Cambridge.

Schmitt, N. (2014). Size and depth of vocabulary knowledge: What the Research Shows. Language Learning, 64(4), 913-951

Schmitt, N., \& Meara, P. (1997). Researching vocabulary through a word knowledge framework: Word associations and verbal suffixes. Studies in Second Language Acquisition, 19, 17-36.

Schmitt, N., Schmitt, D., \& Clapham, C., (2001). Developing and exploring the behavior of two new versions of the vocabulary levels test. Language Testing, 18, 55-88.

Stæhr, L. S. (2008). Vocabulary size and the skills of listening, reading and writing. The Language Learning Journal, 36, 139-152

Stæhr, L. S. (2009). Vocabulary knowledge and advanced listening comprehension in English as a foreign language. Studies in Second Language Acquisition, 31, 577-607.

Wen, W. (2014). Assessing the roles of breadth and depth of vocabulary knowledge in Chinese EFL learners' listening. Chinese Journal of Applied Linguistics, 37(3), 358-372.

Wesche, M., \& Paribakht, T. S. (1996). Assessing second vocabulary knowledge depth versus breadth. Canadian Modern Language Review, 53, 13-4. 